\title{
Anisotropy and Mesophase Formation Towards Carbon Fibre Production from Coal Tar and Petroleum Pitches - A Review
}

\author{
Luiz Depine de Castro*
}

Instituto de Pesquisa e Desenvolvimento/Centro Tecnológico do Exército, Avenida das Américas 28.705, Guaratiba, 23020-470 Rio de Janeiro-RJ, Brazil

\begin{abstract}
A mesofase é o fator determinante para se produzir as propriedades e microestruturas desejadas dos materiais de carbono. A remoção das moléculas mais leves é necessária para sua produção, mas o rendimento pode ser melhorado com a utilização de pressão ou oxidação, antes da remoção das mesmas. Piches anisotrópicos podem ser produzidos através das tradicionais esferas de mesofase de Brooks e Taylor, ricas em resinas $\alpha$, ou evitando-se as mesmas, através de outras técnicas, como a extração com solventes ou agitação intensa, para gerar, quase que exclusivamente, as resinas $\beta$. Piches anisotrópicos, contendo valores próximos a 100\% de resinas $\beta$, têm sido fiados a temperaturas mais baixas, produzindo fibras de carbono de piche de maior qualidade. Estudos recentes mostraram, experimentalmente, porque os piches exibem comportamentos tão diferentes, no que diz respeito à produção da fibra de carbono, quando suas composições variam em termos de resinas $\alpha$ e $\beta$.

Mesophase is a key issue to design carbon materials towards its properties and microstructures. The understanding of this intermediate phase has changed since it was first discovered. The removal of light molecules is necessary to produce mesophase, but the yield can be improved if other techniques, such as pressure and oxidation, can be used before they are carried out of the system, with nitrogen or vacuum. Anisotropic pitches can be produced throughout the traditional Brooks and Taylor mesophase spheres, rich in $\alpha$-resins, or, avoiding them, with other techniques, such as solvent extraction or strong agitation, to generate, almost exclusively, $\beta$-resins. Anisotropic pitches exhibiting almost $100 \% \beta$-resins have been meltspun at lower temperatures, producing pitch carbon fibres of higher quality. Recent studies were able to explain why the behaviour of the pitches is so different, towards the pitch carbon fibre production, when their compositions, in terms of $\alpha$-resins and $\beta$-resins, change.
\end{abstract}

Keywords: mesophase, pitch, carbon fibers, oxidation, pyrolysis

\section{Introduction}

Carbon anisotropy, first observed in $1961,{ }^{1}$ was soon identified as the clue to the development of graphitizable carbons. ${ }^{2}$ This intermediate molecular arrangement was immediately related to liquid crystals, particularly the nematic discotic liquid crystals.

In a very general description of the conversion process, the heat treatment results in volatilization of lower molecular weight components and polymerization, condensation or de-alkylation of the more reactive species. Brooks and Taylor summarized the phenomena saying: "Initially, the mesophase, consisting of planar aromatic compounds of high

*e-mail: depine@centroin.com.br molecular weight, separates in the isotropic liquid as spherical droplets having a considerable degree of molecular order, with the aromatic sheets stacked in parallel array". As the heat treatment progresses, the spherules grow and then coalesce to form large bulk anisotropic regions that separate from the lower-density isotropic pitch phase and slowly settle. Subsequently, as the chemical reactions continue, the entire pitch is generally transformed to a fusible mesophase state (depending on the feedstock composition). Additional heat treatment results in additional polymerization reactions of the mesophase molecules and leads to the formation of very high softening point semicoke and then an infusible anisotropic coke. ${ }^{3,4}$ During carbonization, the intermediate optically anisotropic phase formed can be deformable by shear forces, but 
upon further heating it solidifies to form the optically anisotropic regions in coke. ${ }^{8}$ However, this is the regular trend and many different behaviors have been observed, depending on the composition of the feedstock. Chandrasekhar et al.,$^{5}$ in 1977, gave the first evidence of the thermotropic mesomorphism of carbonaceous mesophase. Mochida et al. ${ }^{6}$ described the aspects related to a real liquid crystal behavior, involving the isotropy/ anisotropy reversible transition while Lewis ${ }^{7}$ described the reversion to isotropy at high temperature.

Brooks and Taylor spheres were soon analyzed by TEM. ${ }^{8}$ After coalescence of the spheres, bulk mesophase presents a significant orientational order (local molecular orientation - $\mathrm{LMO}^{9}$ ), the key to successful graphitization at higher temperature.

During pitches pyrolysis or carbonization, when radical inter- and intra-molecular condensation reactions take place to form semicoke, the systems are almost impossible to study because it is impossible to track the history of individual molecular species. ${ }^{10}$

Ultimately, it is the chemistry of the pyrolysis system that controls the structure and properties of resultant semicokes/ cokes/ carbons, but, the chemistry, in turn, is a function not only of the chemical properties of the original feedstocks, but also of the physical parameters incorporated into the system, such as heating rate, soak time, final reaction temperature and pressure within the system. ${ }^{11}$ Dependent upon how the pyrolysis system is constructed, e.g. whether or not volatile material is lost from or retained within the pyrolysis system, these physical parameters control the chemical composition of the feedstock as it is pyrolysed through to a semicoke. ${ }^{12}$ The physico-chemical behaviour of coking, which also includes flow movement or turbulence within the liquid (fluid) carbonization system, caused by thermal flow and gas evolution from the system, also affects semicoke properties. ${ }^{11}$

Restrictive environmental legislation concerning the emission of toxic and carcinogenic fumes at work and the closing of numerous coke plants in some countries have led to the search for new pitches capable of replacing, at least in part, coal-tar pitches. In this respect, petroleum pitches could be a good alternative to competing in a market, which until now has been exclusively dominated by coal-tar pitches..$^{13}$

Petroleum feedstocks are essentially composed of large polycyclic molecules, with different levels of aromaticity and aliphatic side-chains. Pyrolysis chemistry ultimately leads to the formation of mesogens, which involves the simultaneous dehydrogenation, de- alkylation, condensation and aromatization of the molecules of the feedstock, together with some molecular fragmentation and regrowth. ${ }^{10}$

\section{Characterization of pitches and mesophase solubility}

The two main sources of pitches are the coal tar, from steel industry, and FCC-decant oil, from catalytic cracking of heavy petroleum fractions. An enormous effort has been done to identify the chemical compounds of a pitch, but the huge amount of hydrocarbons present makes this task almost impossible. Several techniques have been used, with some success, to characterize the original pitch and its chemical changes upon pyrolysis such as FT-IR, TG, DTA, NMR, ${ }^{14,15}$ ESR $^{16}$ HPLC, CG$\mathrm{MS}^{17}$ and rheometry but they are very time consuming, expensive, used in particular situations, such as to determine the amount of mesophase, or to achieve information just for groups or "families" of compounds that were, previously and intentionally, separated from a pitch before any technique is applied, or for groups or "families" of compounds that were separated from each other during the analytical process itself. It has been very difficult to follow the chemical composition of a pitch since the beginning of the pyrolysis process up to the final coke produced and to relate the evolution of the chemical composition, since the starting raw material, up to the final properties of a carbon product.

Possibly one of the first techniques used to characterize a pitch and, also, the most used one, until today, is its solubility in solvents. The study of the extractive ability of organic solvents with pitches has been a subject of great interest to study the nature and composition of pitches, classically by using various fractionating schemes, and to follow the progression of carbonization processes. ${ }^{18}$

A decisive improvement was obtained by Diefendorf and Riggs when they discussed the solubility aspects of pitches. ${ }^{19}$ After this work, it was recognized that solubility and mesophase formation were unconnected phenomena and a new generation of solvent fractionated pitches were developed.

Guillén et al. ${ }^{18}$ tested the extractive ability of 27 organic solvents for coal tar pitches, and the reproducibility of the data for the majority of these solvents, using ultrasonic bath. The selected solvents were characterized by lack of reaction between solvent and pitch components, and covered a wide range of dielectric constants, dipole moments, and solubility parameters. The authors concluded that there were not simple relationships between the solubility of coal tar pitch and solvent 
properties like dipole moment, dielectric constant, or solubility parameter. All their experimental results suggested that the difference between extracted fractions (solvents of similar extractive efficiency) lies in the concentration of some of their components but not in the nature of their functional groups.

The most common solvents used, up to now, to characterize pitches are quinoline and toluene, but a tendency exists to substitute quinoline for 1-methyl-2pyrrolidinone, less toxic and cheaper than the former.

The insolubles in quinoline (QI), excluding the primary QI, discussed further in this review, are known as $\alpha$-resin. The fraction of the whole pitch insoluble in toluene, less the QI, is known as $\beta$-resin and the part of the pitch that is soluble in quinoline and soluble in toluene is known as $\gamma$-resin.

The amount of mesophase in a pitch was initially measured by its QI, but soon it was verified that there was not a proper relationship between these two things. ${ }^{20}$ In fact, mainly coal tar pitches may exhibit a meaningful amount of QI, such as soot, catalyst and coke, brought from its production process, without any other treatment had been applied, called as primary QI, having no resemblance whatsoever to the mesophase. Optical microscopy is another technique used to determine the amount of mesophase in pitches. It is a statistic-based technique which accuracy is questioned because the spherules under one micrometer cannot be seen. High speed centrifugation is probably the most accurate technique, not using very sophisticated equipments, employed to determine the mesophase percentage in the pitch, but it is a technique not commonly found in scientific papers probably due to experimental problems, once it is necessary to achieve the phase separation, between isotropic and anisotropic pitch, at high speed and temperature. ${ }^{21}$ It has not been possible, yet, unfortunately, to identify one solvent or a simple and fast analytical technique to identify the amount of mesophase in pitch, accurately, to follow the production of a carbon material. Accurate results have been achieved, but using NMR. ${ }^{15}$

\section{Primary Quinolein Insolubles - Influence on Mesophase Formation}

In 1968, Brooks and Taylor ${ }^{2}$ found a marked association between primary QI particles and mesophase spheres during early stages of mesophase formation. They verified that pitches containing abundant QI particles produced more numerous and smaller mesophase spheres than those where primary
QI particles were less abundant. These QI particles were located predominantly around the surfaces of any mesophase spheres present and they inhibited their regular growth and their coalescence.

Cranmer et al. ${ }^{22}$ identified that dynamic motion in the fluid pitch, rather than the presence of nucleating particles, was the controlling factor in the appearance of mesophase spheres. On the contrary Tillmanns et al. ${ }^{23}$ reported that the presence of primary QI particles accelerated the formation of mesophase as a result of the nuclei abundance.

Stadelhofer ${ }^{24}$ found that the presence of up to 10 wt\% primary QI, either in admixed or natural form, had no accelerating effect on the rate of mesophase formation during the early stages of pitch carbonization while Romovacek et al. ${ }^{25}$ found that the primary QI particles retarded the formation of mesophase, which then appeared at higher temperatures than in the absence of primary QI.

Marsh and Latham ${ }^{26}$ observed that the presence of primary QI on the margins of mesophase spheres not only inhibited coalescence, but also reduced markedly the flow characteristics of the mesophase.

Mamone and Bradshaw ${ }^{27}$ noted that filtration to reduce the primary QI content caused the remaining QI particles to clump and in this condition the effect of QI was lessened unless there was subsequent homogenization, in which case the mesophase domains would become smaller than would otherwise have been the case.

Taylor et al. ${ }^{28}$ found that, even in a QI-rich pitch, between 1 and $10 \%$ of mesophase, spheres were not attached to QI particles at very early stages of mesophase formation. They explained that a few mesophase spheres could escape attachment to QI even where much of the latter was present, because cohesion had to be preceded by a collision, which is a random process. At slightly later stages, virtually all the QI particles were located on the margins of mesophase spheres and were no longer present (or in very small amount) in the unconverted pitch. It followed that the very large number of mesophase spheres formed after this stage could not be nucleated by QI particles. They concluded that QI was not important in the nucleation of mesophase and that it was postnucleation contact between mesophase and QI that lead to their attachment.

Although disclinations occur in mesophase free of QI, Taylor et al. ${ }^{28}$ observed that QI particles were commonly the focus for disclinations. These disclinations and QI particles would, obviously, change the carbon properties and this change may be favorable or unfavorable, depending on the application of this particular mesophase pitch. 
Primary QI is quite undesirable, during the pitch carbon fiber production, not so much for its interference in mesophase formation, but for its damaging effect during the melt spinning stage.

\section{Brooks and Taylor Mesophase}

The Brooks and Taylor mesophase, first identified in $1961,{ }^{1}$ was studied by Diefendorf et al. ${ }^{29}$ and they verified that a minimum molecular weight of $400 \mathrm{amu}$ was needed to prevent volatilization before molecular weight increasing and condensation reactions occur (molecular weight increase). Their studies also indicated that volatilization of light pitch molecules could be more important than polymerization and condensation, in Brooks and Taylor mesophase (BT mesophase) production. Although the removal of low molecular weight species was important, they acted as solvents or plasticizers for the high molecular weight mesogenic species and, without them, the high molecular weight species, the ones about $1000 \mathrm{amu}$, that would stabilize the mesophase structure, would decompose before a sample could be heated hot enough to form fluid mesophase. In their experiments, the same authors verified that the mesogenic species could be disrupted by additions of non-mesogenic species and the amount needed from the last one would increase with difference between the mesophase/isotropic transition temperature and the softening point of the pitch. This was a final proof that mesophase formation was mainly due to the physical separation of the nonmesogenic species rather than chemical reactions, the same authors said.

Several authors confirmed that in a two phase, isotropic $\&$ mesophase pitch, both phases would contain mesogenic $\&$ nonmesogenic species, varying between 400 and 2000 amu, but with different relative concentrations. ${ }^{29-31}$ The coexisting isotropic phase was enriched with molecules of MW less than $1000 \mathrm{amu}$, whereas the corresponding mesophase was enriched with molecules of MW greater than $1000 \mathrm{amu}^{31}$

The thermal conversion of petroleum pitch to mesophase involves both chemical polymerization and de-alkylation reactions. ${ }^{32-34}$ Hence, the development in the pitch of long-range molecular order was attributed to both increasing molecular weight ${ }^{32,33}$ and loss of $\mathrm{sp}^{3}$ type chemical bonding (side chains on aromatic rings). ${ }^{34}$ Such chemical reactions remove mesophase inhibitors and disordering species and lead to the formation of large planar molecules. Based on these data, it was subsequently determined that the de-alkylation reactions, which increase the aromaticity and molecular planarity of the pitch molecules, had only a minor influence on mesophase formation, whereas polymerization reactions, which increase the molecular size, had a major influence on mesophase development. ${ }^{35}$ The relative importance of thermal polymerization and dealkylation reactions would vary somewhat based on the nature of the feedstock. ${ }^{31}$

It is well known that the obtained carbon precursors compositions, and consequently their properties, are mainly dependent on the initial nature of the raw pitches as well as the heat treatment parameters, such as, heating rate, final soaking temperature and soaking duration time. These parameters influence the treated pitch composition, usually expressed through $\alpha, \beta$ and $\gamma$-resins. ${ }^{36}$

Some authors had focused their attention on pitch composition evolution under isothermal heat treatment and how during heat soaking, the three resins development present antagonistic behaviors: the $\gamma$ resins disappearance and the $\alpha$-resins formation lead to a first regime of $\beta$-resins formation followed by a second regime of $\beta$-resins consumption. ${ }^{37}$ Castets et al ${ }^{36}$ investigated the development of these three resins under non isothermal heat treatment and they concluded that a higher temperature level induces a simultaneous increase in $\beta$ and $\alpha$-resins formation while a longer soaking time at lower final heating temperature treatment would lead to less $\alpha$-resins.

One generic explanation of the mesophase formation and carbonization, associated with the evolution of the $\alpha$, $\beta$ and $\gamma$ - resins, was presented by Oberlin et al. ${ }^{38}$ another one was presented by Zander. ${ }^{39}$

Depending on the feedstock and in a schematic way, one can say that when a petroleum pitch is carbonized it develops Brooks and Taylor mesophase spheres (quinoline insoluble) then mosaic islands. Initially the pitch is $100 \%$ $\gamma$-resins (toluene soluble) and at $100 \%$ anisotropy around $65 \%$, or even less, $\alpha$-resins (quinoline insoluble) is present, associated with $\beta$-resins (quinoline soluble - toluene insoluble), whereas $100 \% \alpha$-resins occurs only at solidification (mosaics). ${ }^{38}$

\section{Brooks and Taylor Mesophase and Anisotropy}

Anisotropic pitches produced through Brooks and Taylor mesophase spheres, by a quiescent thermal treatment of pitches, where soon identified as a raw material not very proper for carbon fiber production. Lewis et al. ${ }^{40}$ observed that pitches that do no exhibit Newtonian or plastic flow behavior at the temperature of spinning do not permit fibers to be spun. That is 
why it was decided to agitate the pitch, during mesophase formation, to produce a homogeneous emulsion..$^{40}$ Other researchers also proposed a vigorous stirring of the pitch to produce a homogeneous emulsion and, in some cases, also a sparging gas system to remove the volatiles. ${ }^{41-44}$

Diefendorf and Riggs ${ }^{19}$ proposed to obtain a homogeneous emulsion to be spun throughout the removal of the heaviest and lightest part of the pitch by solvent extraction and the mesophase produced this way was called "neomesophase". Other researchers followed this solvent extraction line to produce anisotropic pitches to be spun. ${ }^{44,46,47}$ In this case, Brooks and Taylor mesophase spheres are absent because they do not precipitate once the pitch is poor in its isotropic phase, i.e., it is composed by more homogeneous molecules. It is a different mesophase obtained with smaller molecular weight molecules than those in BT mesophase and also they are not very well oriented.

In 1991, Ladfi et al. ${ }^{47}$ studied the pitch pyrolysis aiming to understand the behavior of these two resultant pitches towards the carbon fibers production, i.e., Brooks and Taylor mesophase pitches and "neomesophase" pitches. The measurement of the microhardness of these previously mentioned mesophases showed that the second one exhibited a third of the value of the former. ${ }^{47}$ The same authors assured that the first route through a "liquid crystal" state (BT mesophase) was well studied but the second one, leading to anisotropic pitches, more proper to carbon fiber production, was less known, generated pitches exhibiting characteristics similar to those attributable to $\beta$-resins $(\mathrm{QS}$ but TI) and were edge-to-edge type of gels, not liquid crystals. ${ }^{47}$

The main objective pursued by most of the previous researchers has been to produce a spinnable mesophasic pitch and this would mean a pitch as homogeneous as possible, without solid particles at spinning temperature and this temperature should be below $340{ }^{\circ} \mathrm{C}$. On the other hand, this spinnable material should have high average molecular weight and well oriented molecules to produce carbon fiber with good mechanical properties.

In 1991, Romine and McConhaghi ${ }^{48}$ filled a patent where an isotropic mesogens enriched pitch was mixed to solvents. The objective was separate the mesogens by sedimentation or hypercritical conditions to produce a spinnable mesophasic pitch at temperatures lower than $340{ }^{\circ} \mathrm{C}$. Kalback et al. ${ }^{49}$ filled a patent claiming to produce solvated mesophase pitch, which should be spinnable $40{ }^{\circ} \mathrm{C}$ below its precursor. Pursuing this research line, several other patents were filled always claiming to be able to produce another kind of mesophase, called solvated, mesophase. ${ }^{51-55}$ In a general trend a precursor pitch, before or after a heat treatment, isotropic or QI rich material, was mixed with several different solvents. This mixture was heat treated producing the solvated mesophase, able to be spun at very low temperatures and, in some cases, after the solvent removal, the fiber produced was infusible, i.e., it could be carbonized, directly, without having to be stabilized in the presence of any oxygen rich gas..$^{51-55}$

\section{Anisotropic Pitch Production}

\subsection{Introduction}

When one is studying mesophase towards the production of carbon fiber or any carbon material, it is necessary to keep in mind the type of anisotropy, which would be compatible with the desired application, and the reduction of the production costs. It is known that an efficient removal of nonmesogens during preparation provides a mesophase pitch spinnable at moderate temperatures, ${ }^{20,56-59}$ however such procedures eliminate chances for the lighter molecules, in the starting pitch, to be condensed into the mesogen, leading to low mesophase yield, around $20 \%-30 \%$ and increasing the fiber cost production. ${ }^{46}$

In 1968, Brooks and Taylor ${ }^{2}$ commented that the chemical composition of the graphitizable parent feedstock, in terms of its aromaticity, transferable hydrogen content, heteroatom content and catalytic mineral content, dominantly controlled the growth and crystallinity of resultant mesophase and that these aspects ultimately controlled the physical and mechanical properties of manufactured artifacts, and hence applications.

Otani et al. ${ }^{60}$ producing the first pitch carbon fiber, found that a spinnable pitch was produced by the heat treatment of tetrabenzophenazine (TBP) at temperatures above $500{ }^{\circ} \mathrm{C}$ and that this pitch could be spun into fibers of rather larger diameter $(20 \mu \mathrm{m})$ at $410-440{ }^{\circ} \mathrm{C}$ giving a carbon fiber of high tensile modulus. This spinning temperature range was high and TBP was very expensive.

It was known that the amount of heat-treated material, the effect of the confined atmosphere and the heating rate considerably modified not only the heat treatment temperature (HTT), at which all steps occurred, but also the final LMO size. ${ }^{62-70}$ Bonnamy ${ }^{61}$ however, showed that, an increase in the amount of the sample, or a confined atmosphere, or an increase in the heating rate was 
equivalent to a decrease in cross-linking and as a result an increase in the LMO size was produced.

In 2000, Mochida reviewed some of the procedures to prepare mesophase pitch, as precursor for carbon fiber of high performance, as summarized below: ${ }^{71}$

Strehlow $^{72}$ first reported that the mesophase could be separated from the isotropic phase during the heat treatment of coal tar pitch, using high-temperature centrifugation during the heat treatment.

Mochida et al. ${ }^{73}$ found, through the analysis of mesophase pitch, that naphthenic and short alkyl chains groups are essential for the mesophase pitch to keep its low softening point for stable spinning and reasonable stabilization reactivity.

Barr et $a l .{ }^{74}$ established a process to produce mesophase pitch with a softening point below $350^{\circ} \mathrm{C}$ by heating petroleum pitch under a rapid nitrogen flow to remove effectively low molecular weight nonmesogen species, which formed an isotropic phase. It was suggested that the mesophase pitch thus produced showed better spinnability in contrast with a long heattreatment time.

Hoover et ll $^{75}$ assured that the lyotropic nature of the mesophase pitch had been confirmed by addition or removal of the small molecule fractions. The addition of small molecules decreased the stacking and anisotropy while the removal of such components restored the stacking.

Riggs and Diefendorf ${ }^{76}$ introduced solvent extraction to concentrate the suitable fraction of mesophase pitch. An intermediate molecular weight distribution and controlled properties of mesophase pitch could be obtained by extracting two extremes of the components with solvent of different dissolving abilities.

Mochida and Koray ${ }^{77}$ confirmed that the addition of an adequate amount of small molecule or a fraction of smaller molecular species could change the softening point and melt-fluidity maintaining the stacking and removal of a fraction of small molecular species reduced or even removed the fusibility of the pitch.

\subsection{Production routes}

\subsubsection{One step production}

Kershaw et al. ${ }^{78}$ studied the mesophase formation of petroleum pitch, at $400{ }^{\circ} \mathrm{C}$, by two different routes: $(i)$ with nitrogen gas sparging and (ii) vacuum treatment. They verified that the increase in molecular weight (MW) preceded mesophase formation, rather than proceeding concurrently with it, during the heat treatment and that although there was a small difference in average $\mathrm{MW}$ of isotropic and anisotropic phases, this difference was important in mesophase formation. They concluded that the main difference between the two mesophase pitches was the lower softening point and higher solubility for the vacuum produced pitch when compared to the sparged produced one and this fact was in agreement, according to them, with previous studies. ${ }^{79}$ As the lower MW components in pitch were known to inhibit mesophase formation, ${ }^{19,80,81}$ they assumed that the more efficient removal of the lower MW species using vacuum was the reason that allowed mesophase formation to commence earlier in the heattreatment cycle and to proceed more rapidly than with sparging. However, they also observed that the improved properties, for the vacuum mesophase pitch, were reached at the expense of a significantly lower yield due to the loss of many smaller molecuIes. ${ }^{78}$

Pérez et al. ${ }^{82}$ obtained three pitches by applying three different treatments to the same petroleum feedstock: distillation, thermal treatment in a batch reactor with stirring and continuous non-stirring viscoreduction process (without the removal of volatiles) and subsequent flash distillation. The first process removed the light compounds without the generation of toluene insolubles inside the pitch. The second and third processes produced the formation of $\beta$-resins without the formation of any quinoline-insoluble material. The authors verified that the capacity of the pitches to develop mesophase followed the trend third processed pitch, second processed pitch and then the first processed pitch.

Mora et al., ${ }^{83}$ knowing that literature describes at least three different process to separate anisotropic from isotropic phases, e.g., solvent extraction, ${ }^{76}$ supercritical solvent extraction ${ }^{84}$ and high temperature centrifugation, ${ }^{85}$ decided to investigate what they called a new process to obtain mesophase pitches based on the sedimentation of the mesophase. The highest yield in anisotropic phase was obtained, after sedimentation, at $380{ }^{\circ} \mathrm{C}$ for $60 \mathrm{~min}$, and this petroleum-derived mesophase pitch could be easily spun into carbon fibres, in accordance to the authors.

\subsubsection{Two steps production}

Park and Mochida, ${ }^{46}$ to increase the mesophase yield, studied a two-stage preparation of the mesophase pitch using vacuum residue of FCC-decant oil (FCC-DOVR) as the feedstock. The two stages consisted of pressurized condensation, as the first stage, and the rapid concentration of mesogens, under vacuum into the mesophase pitch, as 
the second stage. They concluded that the two-stage preparation was found very effective to increase the yield of spinnable mesophase pitch, of 100 vol\% anisotropy from FCC-DOVR. The two stages pitch preparation showed a slightly lower melting temperature that was favorable for smooth spinning. The heat treatment under pressure, the authors said, decomposed almost completely the paraffinic fractions in the FCC-DOVR, performed dealkylation from alkyl aromatics and polymerized the aromatic components, especially in the lighter fractions, so introducing a more homogeneous distribution of components to improve the yield of mesogen molecules. ${ }^{46}$

Rhee et al. ${ }^{86}$ compared the two-stage heat treatment methods proposed by Park and Mochida ${ }^{46}$ and Lewis and Lewis. ${ }^{87}$ In fact the variations of these two-stage heat treatment methods concerned just the first stage. While Lewis and Lewis ${ }^{87}$ proposed a total reflux to control and minimize the loss of these low boiling components during the first stage of heat treatment, Park and Mochida ${ }^{46}$ proposed that pressure should be applied during the first stage in order to prevent the loss of the volatiles, low molecular weight components, from the reacting pitch. The second stage proposed by Rhee et al. ${ }^{86}$ was common to both research lines and consisted of sparging nitrogen through the pitch to agitate the reacting fluid. The authors concluded that, in general, the highly anisotropic products produced by pressurized heat treatment followed by nitrogen sparging method softened at significantly lower temperatures than those produced by heat treatment under reflux followed by nitrogen sparging technique. The same authors verified that spinnability was easy for the pitches with softening point of $315^{\circ} \mathrm{C}$ and $95 \%$ anisotropy, difficult for pitches with lower softening points but lower anisotropy and impossible for the pitch with softening point of $340{ }^{\circ} \mathrm{C}$.

Oh et al. ${ }^{88}$ investigated the preparation of spinnable mesophase pitch using two-stage heat treatment, which consisted of pretreatment of raw pitch under pressure and successive heat treatment under ambient pressure, after the removal of the gases produced by thermal decomposition. The raw material was heat treated at 420 , 450 and $480{ }^{\circ} \mathrm{C}$ under the pressures of 5,8 and $15 \mathrm{kgf}$ $\mathrm{cm}^{-2}$. The authors noticed that both $\mathrm{C} / \mathrm{H}$ atomic ratio and softening point of the pitch pretreated at $420{ }^{\circ} \mathrm{C}$ showed significant variations with pressure, while the pressure effect was not so dominant at other heat treatment temperature (HTT). Their results indicated that the polymerization and condensation of low-molecularweight components were dominant at $420{ }^{\circ} \mathrm{C}$, and that thermal cracking of high-molecular-weight components, as well as their polymerization, occurred at $450{ }^{\circ} \mathrm{C} .{ }^{96}$ When converting the pitches into mesophase pitches, by successive heat treatment, Oh et al. ${ }^{88}$ verified that those pretreated at $420{ }^{\circ} \mathrm{C}$ could be converted into mesophase at a relatively low temperature, while those pretreated at $450{ }^{\circ} \mathrm{C}$ needed heat treatment at higher temperatures.

\subsection{Different raw materials}

Azami et al. ${ }^{89}$ investigated the behavior of three petroleum pitch samples (A, B and C) with different softening points and aromaticity $(A>B>C)$, being pitch $C$ prepared by the hydrogenation of pitch $\mathrm{B}$. The authors concluded that there was no correlation between the temperature dependence of hydrogen aromaticity and the generation of mesophase embryos, around $420^{\circ} \mathrm{C}$ for pitches $\mathrm{A}$, and $\mathrm{B}$. The increase of hydrogen aromaticity was most likely correlated with the rapid growth of mesophase after $450^{\circ} \mathrm{C}$ for pitches A and B. In pitch C, the mesophase transformation seemed not to occur until the aromatic hydrogen fraction reached nearly the same level to that of pitch A or B, around $450{ }^{\circ} \mathrm{C}$.

In 1991, Azami et al. ${ }^{90}$ compared a coal-tar-derived (pitch A), a petroleum-derived (pitch B) and hydrogenated petroleum-derived- (pitch C) pitches towards mesophase formation. The authors observed that the appearance of mesophase for pitch A was thought to be relatively early because this pitch had little aliphatic carbon and had a high aromaticity. The mesophase appearances in pitches $\mathrm{B}$ and $\mathrm{C}$ did not occur until the aliphatic carbon content (carbon aliphaticity) reached less than $6 \%$ to $10 \% .^{90}$ However, although mesophase started first in pitch A, pitches $\mathrm{B}$ and $\mathrm{C}$ completed their transformation faster than pitch $\mathrm{A} .{ }^{90}$ The same authors explained that in contrast with pitch A, mesophase-composing molecules in pitches $\mathrm{B}$ and $\mathrm{C}$ had a high mobility, and rearrangements were rather easy within the mesophase and this difference in mobility was thought to be reflected in the mesophase formation rate.

Ito $^{91}$ studied the relationship between the anisotropic optical textures and molecular structures of heat-treated coal tar (CTP) and two petroleum pitches (A240 and P4) using UV-Visible and near-IR spectra. He used equation 1, which he claimed had been applied previously to amorphous semiconductors, ${ }^{92,93}$

$\left[F\left(R_{x}\right) h \bar{v}\right] 1 / 2=B(h \bar{v}-\Delta E)$

where $\Delta E$ refers to the band gap and $B$ to the proportional factor that increases with the degree of the ordered structure, to measure the fraction of the absorption band 
due to the lamellar structure $\left[F\left(R_{x}\right)_{L}\right]$. The difference between the observed intensities of the absorption spectra and $\left[F\left(R_{x}\right)_{L}\right]$, was the absorption due to the isolated aromatic molecules $\left[F\left(R_{x}\right)_{A}\right] .{ }^{91}$ Ito chose the values of $\left[F\left(R_{x}\right)_{A}\right]$ and $\left[F\left(R_{x}\right)_{L}\right]$, at $20,000 \mathrm{~cm}^{-1}$ as a measure of the relative fractions for the three pitches. ${ }^{91} \mathrm{He}$ verified that for CTP, the total absorption intensity increased with heat-treatment time until $2 \mathrm{~h}$; this increase he attributed, mainly, to the increase in $F\left(R_{x}\right)_{L}$. In accordance to the author, this implied that the lamellar structure of CTP was converted from the isolated aromatic hydrocarbons. After prolonged heat treatment of CTP, the total absorption intensity decreased due to the decrease in the amounts of the isolated aromatic hydrocarbons. In the case of A240, a similar behavior toward CTP was seen, except all these absorption intensities were weaker than those of CTP. Ito assumed that this would be reasonable if the size of the aromatic hydrocarbons in heat-treated A240 was smaller than that in the heat-treated CTP. ${ }^{91}$ On the other hand, the change in these absorption intensities of the heat-treated $\mathrm{P} 4$ seemed to be quite different from those of CTP and A240.

In 1999, Martínez-Escandell et al. ${ }^{94}$ studied the pyrolysis of three types of petroleum feedstocks (R1-aromatic, R2low aromaticity and R3 - almost totally aliphatic feedstock) to understand the effect of the initial aromaticity of the raw material on the mesophase formation. Variations were introduced into the maximum pyrolysis temperature $(\mathrm{T})$ $420-480{ }^{\circ} \mathrm{C}$, the pressure (P) 0.1-1.0 MPa, and soak time $0-12 \mathrm{~h}$, in various combinations. The authors concluded that for semicokes from R1 (the most aromatic), yields were dominantly a function of pressure, with little influence of temperature and soak time. For semicokes from R2 (intermediate aromaticity), yields were dominantly a function of pressure and temperature, with little influence of soak time. For semicokes from R3 (least aromatic), yields were dominantly a function of temperature and soak time, with little influence of pressure. ${ }^{15}$ The same authors concluded that R1 (most aromatic feedstock) produced semicokes with a high aromaticity and flow domain textures while R3 (most aliphatic) produced semicokes with the lowest aromaticity and an optical texture of coarse mosaics. R2 (intermediate aromaticity) reacted more slowly than expected to give highly ordered mesophase. ${ }^{94}$

In 2000, Torregrosa-Rodriguez et al. ${ }^{95}$ using exactly the same feedstocks of Martínez-Escandell et al. ${ }^{94}$ continued the investigations of the latter to understand the effect of the initial aromaticity of the raw material on the mesophase formation. The same research conditions were used in both cases and the former authors concluded that at the completion of the pyrolysis reactions, semicokes from the two petroleum residues possessed very similar aromaticity, despite significant differences in the initial aromaticity of the parent feedstocks.

\section{Heat treatment Under Oxidizing Atmosphere}

\subsection{Introduction}

Although carbon fibers exhibit fantastic mechanical properties, its production cost is, still, avoiding the widespread use of this material. Cost reduction can be achieved by improvements in production technology, such as the reduction of stabilization time, but also by increasing the yield in each production step. The ordinary distillation of a decanted oil from FCC, only results in $25 \%$ to $30 \%$ yield of a starting isotropic pitch. Cross-linking, caused by oxidizing atmosphere, may be an option to increase the molecular weight and increase the distillation yield.

Molecular cross-linking induced by oxygen functionality ${ }^{96,97}$ at low temperatures increases the molecular weight of some molecules, preventing their distillation and removal during the carbonization stage, however, such treatment results in a viscosity increase and, simultaneously, the lamellar orientation of the aromatic molecules becomes more difficult to achieve, suggesting it would suppress the growth of mesophase spheres in the isotropic matrix..$^{98}$

Current studies are mainly concerned with the airblowing pitches used as precursors of isotropic carbon fibres ${ }^{99-101}$ and relate to pitch ability for spinning, ${ }^{102}$ but this treatment has also been successfully applied in manufacturing paving asphalts, ${ }^{103}$ in preparing precursors for isotropic carbon materials ${ }^{104}$ and in raising the softening point of coal tar and petroleum feedstocks. ${ }^{105,106}$

Some researchers accept that the reactions promoted by air blowing may take place in two main consecutive steps. The first would be characterized by an increase in weight due to oxygen uptake, mainly at the naphthenic and aliphatic carbon atoms. The extent to which this occurs mainly depends on the temperature of the air blowing. ${ }^{107-12}$ The second step would involve weight loss due to the decomposition of the oxygen-containing functional groups generated during the first step. ${ }^{97,111-114}$ As a result new C-C bonds are formed, releasing $\mathrm{CO}$ and $\mathrm{CO}_{2}$.

Besides all these direct applications for air blown pitches, there is also a large chance of using this technique to produce raw materials that could be used as mesophase or anisotropic pitches precursors. Theoretically, it would be possible to increase the average molecular weight of a low molecular weight pitch before anisotropy is produced in order to increase the anisotropy yield. 


\subsection{Production Aspects}

It is never easy to prepare such an isotropic pitch from coal tar by conventional methods, such as distillation or heat treatment in an inert atmosphere, because mesophase spheres appear very easily by the heating above a certain level of temperature, commented Maeda. ${ }^{99}$

In 1993, Maeda et al., ${ }^{99}$ aiming to produce a general purpose carbon fiber (GPCF) precursor pitch exhibiting a softening point around $280^{\circ} \mathrm{C}$, chose a high temperature range of 330 and $380{ }^{\circ} \mathrm{C}$ for the air blowing of less reactive coal tar. The authors verified that air blowing markedly increased the softening point, contents of insoluble fractions, and atomic ratio $\mathrm{C} / \mathrm{H}$ according to the severity of the treatment conditions. They also verified that after a heat treatment of $14 \mathrm{~h}$, the softening points of the air blowing pitches rose very rapidly, with some induction period for the thermal condensation being suggested. In contrast, their QI contents and anisotropic percents started to increase from the initiation of heat treatment, then increased very rapidly between 7 to $14 \mathrm{~h}$, except for the anisotropic content of the pitch blown at $360{ }^{\circ} \mathrm{C}$ for $4 \mathrm{~h} .{ }^{99}$ The authors concluded that air blowing suppressed the development of anisotropy while blowing was continued, however, successive heat treatment allowed the development of mesophase spheres, indicating that no structural inhibition for the development was introduced except for a very severe air blowing. ${ }^{99}$

In 1993, Zeng et al. ${ }^{101}$ knowing that higher oxidation reactivity of petroleum pitches had been reported to originate from their aliphatic natures, ${ }^{96,104,115}$ investigated the influence of the structural characteristics of pitches on their oxidation reactivity in the air blowing, at 330 ${ }^{\circ} \mathrm{C}$, using three different pitch samples: a QI-free coal tar pitch (NP80-1), its hydrogenated one (NHP-1), and a petroleum pitch (A60-1). NP80 exhibited the most rapid rise of the softening point among the three pitches while NHP-1 exhibited the slowest one. NP80-1 and A60-1 exhibited fully isotropic optical texture and a few mesophase spheres were found in NHP-1. The heaviest fraction, QI, significantly increased in two coal tar pitches, especially in NHP-1, while only a few percent was produced in the petroleum pitch, A60-1. Coal tar pitches significantly increased molecular weights while the petroleum pitch did a little. ${ }^{101}$

Choi et al. ${ }^{107}$ investigated the kinetics of TI formation from coal tar (KCTP) and petroleum (PP) pitch. They verified that there was no appreciable dependency on the yield of TI fraction (YTI) with the volumetric gas flow rate $(\mathrm{F})$, for a range from 100 to $1000 \mathrm{~cm}^{3} \mathrm{~min}^{-1}$, but there was a slight dependency of YTI with the initial pitch load (WO). The same authors determined that YTIs for the air blowing KTCP, at $633 \mathrm{~K}$, were about $20 \%$ higher than those for a nitrogen blowing KTCP, at $713 \mathrm{~K}$, in spite of the lower reaction temperature for the former.

Yamaguchi et al. ${ }^{116}$ modeled the air-blowing reactions to clarify their paths for various model compounds, with 2-3 rings of aromatic hydrocarbons, as starting materials. The air-blowing reactions were followed by ESR, FD-MS, CG-MS, NMR and FT-IR and the authors concluded that when subjected to oxidation in air at $330{ }^{\circ} \mathrm{C}$, alkyl-substituted aromatic compounds polymerized with methylene, biphenyl-type and ether bonding, leading the methylene to partially change into carbonyl during the air-blowing reaction. Therefore, the pitches containing alkyl-substituted compounds were the most effective source materials for rising the softening point, increasing molecular weight and suppressing anisotropic texture.

Fernández et al. ${ }^{117}$ studied the effects of air-blowing on the structure and pyrolysis behaviour of a binder coal tar pitch (CTPA) and an impregnating coal tar pitch (CTPB). They concluded that the formation of cross-linked molecules could delay mesophase formation because needed bond cleavage associated with high-viscosity system, however a mild air-blowing of pitch resulted in a significant increase of carbon yield without destroying the ability of pitch to form anisotropic carbons and airblowing of pitch could prevent pitch swelling.

Prada et al. ${ }^{118}$ instead of treating the pitch, decided to air-blown the parent tar to reduce costs and to obtain pitches of high carbon yield. An industrial tar was airblown under a pressure of $0.5 \mathrm{MPa}$, at temperatures of $275-325{ }^{\circ} \mathrm{C}$ and air flows of $60-120 \mathrm{l} \mathrm{h}^{-1}$. The authors verified that the pitch yield decreased with the extent of treatment, however, in all the experiments it was over $83 \mathrm{wt} \%$, this being much higher than those obtained industrially by fractionated distillation and subsequent thermal treatment $(\sim 50 \mathrm{wt} \%)$ and the pitches obtained by this procedure were totally isotropic. The variations in toluene insolubles and carbon yields showed that, as reaction time increased, air-blowing produced a significant increase in both of these parameters, becoming more important in the later stages of the treatment. ${ }^{118}$ They observed that the ability of pitches to form mesophase was also affected by the severity of the air-blowing. At $450{ }^{\circ} \mathrm{C}$, pyrolysis product from parent tar initiated the generation of mesophase in the form of small spheres while pyrolysis products from air-blown pitches, at $300^{\circ} \mathrm{C}$ and $325^{\circ} \mathrm{C}$, did not generate mesophase when the mentioned temperature was reached. However, 
at $450{ }^{\circ} \mathrm{C}$ and $30 \mathrm{~min}$ of soak time, all the pyrolysis products had initiated the formation of mesophase. ${ }^{118}$ Both coalesced mesophase and mesophase spheres became smaller in size as the air-flow increased. ${ }^{118}$

Machnikowski et al. ${ }^{119}$ investigated the structural peculiarities of pitches, which were relevant to the mechanism of mild oxidation and, in consequence, control the carbonization behaviour of air-blown derivatives. The authors reduced the compositional complexity characteristic of coal tar pitch using extrographic fractions, which concentrate classes of compounds of similar functionality and molecular weight. They verified that the oxidation of different coal-tar pitches to a moderate extent, corresponding to the increase in softening point to about $175^{\circ} \mathrm{C}$, modified extrographic fraction distribution as a result of polymerization and/ or cross linking of constituents, but did not affect essentially the chemical composition of corresponding fractions. Among different classes of compounds present in coal- tar pitch, low molecular weight cata-condensed PAHs and basic nitrogen and phenolic compounds were constituents preferentially polymerized in the mild oxidation, in contrast to peri-condensed structures, which were resistant to the treatment. ${ }^{119}$

Bermejo et al. ${ }^{120}$ studied the air blowing technique on anthracene oil. It was known that when severe air-blowing conditions were used, the resultant products gave isotropic residues on pyrolysis. ${ }^{121}$ They verified that, after a heat treatment, all the parent and air-blown products were still isotropic under the optical microscope. Consequently the thermal treatment, even under the severest conditions $\left(390^{\circ} \mathrm{C}\right.$ for $5 \mathrm{~h}$ ), did not originate mesophase. The value of some of the characteristic parameters of the pitches (SP, TI and CY), increased significantly with thermal treatment. However, the increase in the parameters was not closely related to the temperature and time of treatment. No relationships were found between the values of the parameters in the parent and treated samples. The increase seemed to depend rather on the air-blowing history of the samples. ${ }^{120}$

\section{Conclusions}

The production of a specific high quality carbon material, such as continuous pitch based carbon fiber is directly related with the type of mesophase generated inside the pitch. The filament production and subsequent production steps parameters are critical to the fiber costs and its mechanical properties. These parameters are completely dependent on the type and characteristics of the anisotropic pitch precursor.

The characterization of pitches is still a major issue once a large part of their molecules are above $1000 \mathrm{amu}$, their chemical composition varies significantly with the feedstock and these materials are a mixture of more then 2000 chemical compounds, making virtually impossible to follow each one during carbonization step. Although many techniques can be used to produce information on the pitch chemical composition, the solvent solubility is, still, the most used one, because is cheaper and faster than the other ones. The use of more sophisticated analytical techniques may be helpful in the fully understanding of the chemical evolution of pitches under pyrolysis.

Primary QI do not nucleate mesophase spheres, but it is responsible for producing disclinations and in affecting the properties of the carbon materials. Primary QI are particularly damaging in pitch carbon fibre production.

Brook and Taylor mesophase and anisotropy were synonyms for a long time, but it has been shown that not every anisotropic pitch has to be a mosaic or domain produced throughout the coalescence of BT mesophase spheres, under quiescent thermal treatment. It is possible to produce anisotropic pitches, using different techniques, mainly composed of $\beta$-resins, instead of $\alpha$-resins or a mixture of both, to produce higher quality pitch carbon fibers.

Mesophases produced by different techniques are not the same but most of researchers still believe that all of them are liquid crystals and not edge-to-edge type of gels, as it was proposed once.

Except if someone comes out with a brand new and innovative idea, nobody would thing, nowadays, of producing pitch carbon fiber in just one step due to the low yield and consequent high costs. An initial step to promote chemical reactions is strongly advised in the literature.

The oxidation of the feedstock to increase the pitch yield is a desperate attempt to reduce the carbon fiber producing costs and its use should be well considered.

Most of the research work has been dedicated, up to now, to coal tar and synthetic pitches, what is very understandable. The feedstock for the first one is highly aromatic with some reactivity, so being able to produce, at least theoretically, a mesophase pitch at low cost. The feedstock for the second is fully or almost fully aromatic and the catalyst cost should be compensated by the higher quality of the carbon fiber produced. However, it seems that there is, lately, an increasing interest in studying and in using petroleum pitches as raw materials to produce carbon fibers and other carbon products. Possibly this interest is based in the studies that have shown that the ability of producing anisotropic pitches is based not only in the high initial aromaticity of the precursor, but also in its reactivity. In addition, petroleum pitch is less detrimental to environment than coal tar pitch and, nowadays, this is a strong argument. 
The chemical and physico-chemical properties for a pitch to produce a continuous high quality carbon fiber are still well-kept information of very few companies supplying the market.

\section{Acknowledgment}

The author thanks Petrobras - Petróleo Brasileiro S.A. (Project 6502182032) for its support to this work.

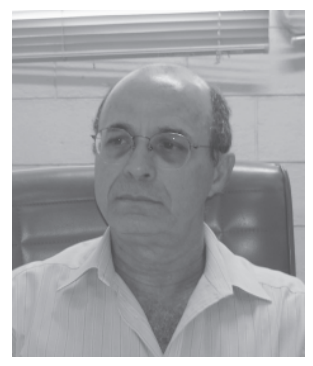

Luiz Depine de Castro concluded his Ph.D. in Materials Science, at University of Bath, Great Britain, in 1991. Presently, he is doing consultancy, for the Centro Tecnológico do Exército (CTEx), in 2 research projects with Petrobras and FINEP, which aim to develop petroleum pitches, carbon fiber and advanced carbon materials. He is the author of 1 international patent, 17 papers in journals and conferences and, also, 19 other technical productions. Between 1982 and 1988 he was in charged of 4 research projects and headed the carbon/graphite group of CTEx. He works in the Materials Science and Materials Chemistry area with emphasis in pitch, petroleum pitch, coke, carbon fiber and graphite.

\section{References}

1. Taylor, G.H.; Fuel 1961, 40, 465.

2. Brooks, J. D.; Taylor, G. H.; Chem. Phys. Carbon 1968, 4, 243.

3. Greinke, R. A.; Chem. Phys. Carbon 1994, 24, 1.

4. Martín, Y.; García, R.; Keating, P.; Snape, C. E.; Moinelo, S. R.; Energy Fuels 2000, 14, 380.

5. Chandreasekhar, S.; Sadashiva, B. K.; Suresh, K. A.; Pramana 1977, 9, 471.

6. Mochida, I.; Tamaru, K.; Korai, Y.; Carbon 1984, 22, 181.

7. Lewis, I. C.; Carbon 1980, 18, 191.

8. Hurt, R. H.; Hu, Y.; Carbon 1999, 37, 281.

9. Oberlin, A.; Chem. Phys. Carbon 1989, 22, 1.

10. Rodríguez-Reinoso, F.; Martínez-Escandell, M.; Torregrosa, P.; Marsh, H.; Gómez de Salazar, C.; Romero-Palazón E.; Carbon 2001, 39, 61.

11. Martínez-Escandell, M.; Torregrosa, P.; Marsh, H.; RodríguezReinoso, F.; Santamaría-Ramírez, R.; Gómez-De-Salazar, C.; Romero-Palazón, E.; Carbon 1999, 37, 1567.

12. Santamaría-Ramírez, R.; Romero-Palazón, E.; Gómez-deSalazar, C.; Rodríguez-Reinoso, F.; Martínez-Saez, S.; Martínez-Escandell, M.; Marsh, H; Carbon 1999, 37, 445.
13. Pérez, M.; Granda, M.; Garcia, R.; Santamaría, R.; Romero, E.; Menéndez, R.; J. Anal. Appl. Pyrolysis 2002, 63, 223.

14. Alcañiz-Monge, J.; Cazorla-Amorós, D.; Linares Solano, A.; Fuel 2001, 80, 41.

15. Harvey, T. G.; West, G. W.; Carbon 1996, 34, 275.

16. Ito, O.; Kakuta, T.; Lino, M.; Carbon 1989, 27, 869.

17. Martín, Y.; García, R.; Keating, P.; Snape, C. E.; Moinelo, S. R.; Energy Fuels 2000,14, 380.

18. Guillén, M. D.; Blanco, J.; Canga, J. S.; Blanco, C. G.; Energy Fuels 1991, 5, 188.

19. Diefendorf, R. J.; Riggs, D. N.; U.S. Patent 4,208,267, 1980.

20. Chwastiak, S.; Lewis, I. C.; Carbon 1978, 16, 156.

21. Kim, C. J.; Ryu, S. K.; Rhee, B. S.; Carbon 1993, 31, 833.

22. Cranmer, J. H.; Plotzker, I. G; Peeble, L. H and Uhlmann, D.R.; Carbon 1983, 21, 201.

23. Tillmanns, H.; Pietzka, G.; Pauls, H.; Fuel 1978, 57, 171.

24. Stadelhofer, J. W.; Fuel 1980, 59, 360.

25. Romovacek, G. R.; McCullough, J. P.; Perrotta, A.J.; Fuel 1983, 62, 1236.

26. Marsh, H.; Latham, C. S.; Symposium Series, n. 1, 3, American Chemical Society: Washington, DC, 1986.

27. Mamone, V.; Brashaw, W.; Extended Abstracts, 16th Conference on Carbon, Am. Carbon Society, 1983.

28. Taylor, G. H.; Pennock, G. M.; FitzGerald J. D.; Brunckhorst, L. F.; Carbon 1993, 31, 341.

29. Diefendorf, R. J.; Yen, T. F.; Needles, H. L.; Shcaefgen, J. R.; Jaffe, M.; Logothetis, A. L.; ACS Symposium Series ( based on 186th Meeting of the American Chemical Society), Jett Jr., C. A., ed.; Washington D.C.,1983.

30. Chen, S. H.; Diefendorf, J. J.; Extended Abstracts, Carbon 84 , International Carbon Conference, Bordeaux, France, 1984.

31. Greinke, R. A.; Chem. Phys. Carbon 1994, 24, 1.

32. Greinke, R. A.; Carbon 1986, 24, 677.

33. Greinke, R. A.; Lewis, I. C.; Carbon 1984, 22, 305.

34. Riggs, D. M.; Diefendorf, R. J.; Extended Abstracts 14th Biennial Conference on Carbon, American Carbon Conference, 1979.

35. Greinke, R. A.; Carbon 1990, 28, 701.

36. Castets, K.; Daguerre, E.; Py, X.; Fuel 2001, 80, 2075.

37. Py, X.; Daguerre, E.; Fuel 2000, 79, 591.

38. Oberlin, A.; Bonnamy, S.; Rouxhet, P.G.; Chem. Phys. Carbon 1999, $26,1$.

39. Zander, M. In Science of Carbon Materials 2000; Marsh, H.; Rodrigues-Reinoso, F., eds.; Univ. Alicante Publ., 2000, p. 205.

40. Lewis, I. C.; McHenry, E. R.; Singer, L. S.; U.S. Patent 3,976,729, 1976.

41. McHenry, E. R.; U. S. Patent 4,026,788, 1977.

42. Singer, L. S.; Carbon 1978, 16, 409 .

43. Singer, L. S.; Lewis, I. C.; Carbon 1978, 16, 417.

44. Oshida K.; Bonnamy, S.; Carbon 2002; 40, 2699.

45. Honda, H.; Carbon 1988, 26, 139.

46. Park, Y. D.; Mochida, I.; Carbon 1989, 27, 923. 
47. Lafdi, K.; Bonnamy, S.; Oberlin, A.; Carbon 1991, $29,831$.

48. Romine, H.E.; McConhaghi, J. R.; U.S. Patent 5,032,250, 1991

49. Kalback, W. M.; Romine, H. E.; Bourrat, X. M.; U.S. Patent 5,259,947, 1993.

50. Southard, W. M.; Nanni, E. J.; Carel, M. W.; U.S. Patent 5,437,780, 1995.

51. Romine, E. H.; Southard, W. M.; Nanni, E. J.; Carel, M. W.; U. S. Patent 5,489,374, 1996.

52. Romine, E. H.; Nanni, E. J.; Carel, M. W.; Southard, W. M.; U. S. Patent 5,501,788, 1996.

53. Kalback, W. M.; Romine, E. H.; Bourrat, X. M.; U.S. Patent 5,538,621, 1996.

54. Romine, E. H.; U.S. Patent 5,540,832, 1996.

55. Romine, E. H.; U.S. Patent 5,540,903, 1996.

56. Chwastiak, S.; British Patent Application, GB 2005298A, 1979.

57. Chwastiak, S.; Japanese Patent 54-55625, 1979.

58. Riggs, D. M.; Diefendorf, R. J.; Extend Abstracts 16th American Carbon Conference, 1983.

59. Yamada, Y.; Honda, H.; Japan Patent 58-18421, 1983.

60. Otani, S.; Okubo, Y.; Koitabashi, T.; Bull. Chem. Soc. Jpn 1970, 43, 3291.

61. Bonnamy, S.; Carbon 1999, 37, 169.

62. Oberlin, A.; Boulmier, J. L.; Villey, M. In Kerogen - Insoluble Organic Matter from Sedimentary Rocks; Durand B., ed., Technip: Paris, 1980, p.191.

63. Bourrat, X.; Oberlin, A.; Escalier, J. C.; Compte Rendu de l'Académie de Sciences, Paris, 1984, vol. 298, p. 695.

64. Bourrat, X.; Oberlin, A.; Escalier, J. C.; Fuel 1986, 65, 1490.

65. Oberlin, A.; Bonnamy, S.; Bourrat, X.; Monthioux, M.; Rouzaud, J. N. In ACS Symp, Series n. 303 (Petroleum Derived Carbons); Bacha, J. D.; Newman, J. W.; White, J. L., eds., American Chemical Society: Washington DC, 1986, p. 85.

66. Monthioux, M.; Oberlin, M.; Oberlin, A.; Bourrat, X.; Boulet, R.; Carbon 1982, 20, 167.

67. Bonnamy, S.; Thèse d'État, Université d'Orléans, France, 1987.

68. Bonnamy, S.; Oberlin, A.; Proc. Carbon 88, Newcastle-uponTyne:UK, 1988, p. 314.

69. Bonnamy, S.; Obelin, A.; Carbon 1982, 20, 499.

70. Villey, M.; Thèse d'État, Université d'Orléans, France, 1979.

71. Mochida, I.; Koray, Y.; Ku, C.; Watanabe, F.; Sakai, Y.; Carbon 2000, 38, 305 .

72. Strehlow, R. A.; US Oak Ridge National Laboratory Report No. ORNL - 4622, Molten Salt Reactor Program, Semi Annual Progress Report, Period Ending August 31, 135, 1970.

73. Mochida, I.; Kubo, K.; Fukuda, N.; Takeshita, T.; Takahishsi, R.; Carbon 1975, 13, 135.

74. Barr, J.; Chwastiak, S.; Didchenko, R.; Lewis, I.; Lewis, R.; Singer, L.; Appl. Polym. Sym. 1976, 29, 161.

75. Hoover, D. S.; Davis, A.; Perrota, A. J.; Spackman, W.; Extended Abstracts Biennial Conference on Carbon, 1979, p. 393.

76. Riggs, D. M.; Diefendorf, R. J.; U. S. Patent 4,208,267, 1980.
77. Mochida, I.; Koray, Y.; Nenryo-Kyokaishi 1985, 64, 796.

78. Kershaw, J. R.; Black, K. J. T.; Jaeger, H. K.; Willing, R. I.; Hanna, J. V.; Carbon 1995, 33, 633.

79. Park, Y. D.; Korai, Y.; Mochida, I.; J. Mat. Sci. 1986, $21,424$.

80. Venner, J. G.; Diefendorf, R. J.; Am. Chem. Soc. Symp. Ser. 1984, 260, 219.

81. Lewis, I. C.; Fuel 1987, 66, 1527.

82. Pérez, M.; Granda, M.; Garcia, R.; Santamaría, R.; Romero, E.; Menéndez, R.; J. Anal. Appl. Pyrolysis 2002, 63, 223.

83. Mora, E.; Blanco, C.; Santamaría, R.; Granda, M.; Menéndez, R.; Carbon 2003, 41, 445.

84. Hutchenson, K. W.; Roebers, J. R.; Thies, M. C.; Carbon 1991, 29, 215.

85. Singer, L. S.; Riffle, D. M.; Cherry, A. R.; Carbon 1987, 25, 249.

86. Rhee, B.; Chung, D. H. and In, S. J.; Carbon 1991, 29, 343.

87. Lewis, R. T.; Lewis, I. C.; U. S. Patent 4,303,631; 1981.

88. Oh, S.; Yoon, S. H.; Dong, G.; Park, Y. D.; Carbon 1991, $29,1009$.

89. Azami, K.; Yokono, T.; Sanada, U.; Uemura, S.; Carbon 1989, 27,177

90. Azami, K.; Yamamoto, S.; Yokono, T. and Sanada, Y.; Carbon 1991, 29, 943.

91. Ito, O.; Carbon 1993, 31, 401.

92. Cornell, G. A. N.; Topics in Applied Physics, Brodsky, M. H., ed., Springer- Verlag: Berlin, 1979, vol. 36, p.73.

93. Ozaki, J.; Nishiyama, Y.; Carbon 1987, 25, 697.

94. Martínez-Escandell, M.; Torregrosa, P.; Marsh, H.; RodríguezReinoso, F.; Santamaría-Ramírez, R.; Gómez-De-Salazar, C.; Romero-Palazón, E.; Carbon 1999, 37, 1567.

95. Torregrosa-Rodríguez, P.; Martínez-Escandell, M.; RodríguezReinoso, F.; Marsh, H.; Gómez de Salazar, C.; Romero Palazón, E.; Carbon 2000, 38, 535.

96. Barr, J. B.; Lewis, I. C.; Carbon 1978, 16, 439.

97. Yanasigawa, K.; Suzuki, T.; Fuel 1993, 72, 25.

98. Fitzer, E.; Mueller, K.; Schaefer, W.; Chem. Phys. Carbon 1971, 7, 237.

99. Maeda, T.; Zeng, S. M.; Tokumitsu, K.; Mondori, J.; Carbon 1993, 31, 407.

100. Zeng, S. M.; Maeda, T.; Mondori, J.; Tokumitsu, K.; Mochida, I.; Carbon 1993, 31, 413.

101. Zeng, S. M.; Maeda, T.; Tokumitsu, K.; Mondori, J.; Mochida, I.; Carbon 1993, 31, 421.

102. Fernández, J. J.; Figueiras, A.; Granda, M.; Bermejo, J. and Menéndez, R.; Carbon 1995, 33, 295.

103. Barth, E. J.; Asphalt Science and Techology, Gordon \& Breach: New York, 1962, p. 386.

104. Otani, S.; Carbon 1965, 3, 31.

105. Abraham, H.; Asphalt and Allied Substances, Van Nostrand: New York, 1961, vol. II, p. 98.

106. Baum, L. A. H.; U. S Patent 3,725,240, 1973.

107. Choi, J. H.; Kumagai, H.; Chiba, T.; Sanada, Y.; Carbon 1995, 33,109 . 
108. Matsumoto, T.; Mochida, I.; Carbon 1992, 30, 1041.

109. Yanagida, K.; Sasiki, T.; Tate, K.; Sakanishi, A.; Korai, K.; Mochida, I.; Carbon 1993, 31, 577.

110. Drbohlav, J.; Stevenson, W. T. K.; Carbon 1995, 33, 693.

111. Drbohlav, J.; Stevenson, W. T. K.; Carbon 1995, 33, 713.

112. Metzinger, T. H.; Hüttinger, K. J.; Carbon 1997, 35, 885.

113. Miura, K.; Nakagawa, H.; Hashimoto, K.; Carbon 1995, 33, 275.

114. Lavin, J. G.; Carbon 1992, 30, 351.

115. Sawa, M.; Nishizawa, S.; 15th Annual Meeting on Carbon, Japanese Carbon Society, Extended Abstracts, 1988.

116. Yamaguchi, C.; Mondori, J.; Matsumoto, A.; Honma, H.; Kumagai, H.; Sanada, Y.; Carbon 1995, 33, 193.
117. Fernández, J. J.; Figueiras, A.; Granda, M.; Bermejo, J.; Menéndez, R.; Carbon 1995, 33, 1235.

118. Prada, V.; Granda, M.; Bermejo, J.; Menéndez, R.; Carbon 1999, 37, 97.

119. Machnikowski, J.; Kaczmarska, H.; Gerus-Piasecka, I. A.; Díez; M. A.; Alvarez, R.; Garcia, R.; Carbon 2002, 40, 1937.

120. Bermejo, J.; Fernández, A. L.; Granda, M.; Rubiera, F.; Suelves, I.; Menéndez, R.; Fuel 2001, 80, 1229.

121. Fernández, A. L.; Granda, M.; Bermejo, J.; Menéndez, R.; Carbon 2000, 38, 1315.

Received: January 27, 2006 Published on the web: July 20, 2006 